\title{
Crença em símbolos espirituais no processo de envelhecimento
}

\author{
Belief in spiritual symbols \\ in the aging process
}

FisiSenectus . Unochapecó Ano 1, n. 1 - Jan./Jun. 2013 p. $51-60$

\section{Leoni Teresinha Zenevicz}

Doutora em Gerontologia Biomédica pela PUCRS. Docente na Universidade Federal da Fronteira Sul (UFFS).

\section{Walter Ferreira dos Santos}

\section{Resumo}

Objetivos: este estudo teve o objetivo de identificar e conhecer a crença dos idosos em símbolos espirituais que expressam sua espiritualidade e religiosidade, utilizando-os em diferentes situações para vencer os obstáculos da idade, fortalecendo-os e proporcionando bem-estar físico, mental e espiritual. Sabe-se que o ser humano é um ser religioso e os símbolos sagrados são respeitados por representarem a existência de uma força superior acenando a possibilidade do homem conectar-se com o divino, ocupando um lugar de destaque na vida terrena. Materiais e métodos: este estudo foi observacional do tipo transversal, realizado na cidade de Chapecó (SC), no período de julho de 2008 a janeiro de 2009. Fez parte da amostra 2.160 pessoas de idades 20 a 39, de 40 a 59 e acima de 60 anos, implicando em 720 indivíduos entrevistados em cada faixa etária nas suas residências. Na conferência do banco de dados, optou-se pela análise descritiva univariada, com a obtenção das frequências simples e relativas para cada variável investigada, e os dados finais receberam tratamento estatístico utilizando-se o software SPSS 13.0 (Statistical Package to Social Sciences for Windows). Resultados: a partir dos resultados, observou-se que $68,5 \%$ dos pesquisados acreditam em símbolos espirituais. 47,3\% apontam a Bíblia como símbolo mais reverenciado em que depositam sua crença e fé e 73,9\% confirmam que os símbolos os ajudam no enfrentamento das diferentes situações da vida cotidiana. Conclusão: frente aos achados, pode-se inferir que, com o aprofundamento do envelhecimento, os idosos tornam-se mais espiritualizados e olham com mais serenidade para a vida ampliando a fé, aproximando-se de Deus, acreditando nos símbolos e forças espirituais, exercitando mais suas práticas religiosas (preces, orações, súplicas).

\section{Palavras-chave}

Símbolos. Espiritualidade. Idosos. 


\begin{abstract}
Objective: this study aimed to identify and know the elderly beliefs in spiritual symbols that express their spirituality using the symbols in different situations in order to overcome obstacles of age strengthen them and providing physical, metal and spiritual well-being. It is known that the human being is a religious being and the sacred symbols are respected by representing the existence of a superior strength waving the possibility of the mankind connect to the divine, taking a prominent place in earthly life. Materials and methods: this study was a observational cross sectional, done in the city of Chapecó (SC), in the period from July 2008 to January 2009. It was part of the sample 2160 peoples aged 20 to 39, 40 to 59 and above 60 years old, involving 720 indivuduals interviewed in each age group in their residence. In the database checking, it was opted for univariate descriptive analysis, with the obtaining simple and relative frequencies to each investigated variable, and the final data received statistical processing using SPSS 13.0 software (Statistical Package to Social Sciences for Windows). Results: based on the results, observed that $68,5 \%$ of those surveyed belive in spiritual symbols. $47.3 \%$ indicate the Bible as the most revered symbol in that they place their beliefs and faith, as well as $73.9 \%$ confirm that the symbols help them facing may different situations of a daily life. Conclusion: forward to the findings, it can infer that with the deeping of aging, the elderly become more spiritualized and look with more serenity to the life, extending the faith, approaching God, believing in symbols and spiritual forces, exercising more their religious practical (prayers, supplications).
\end{abstract}

\title{
Keywords
}

Spirituality. Elderly. Symbols.

\section{Introdução}

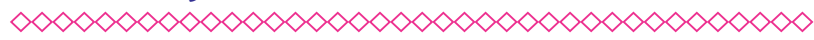

0 envelhecimento é uma realidade mundial. Para 2050, os dados estatísticos projetam um biIhão e novecentos milhões de pessoas com 60 anos ou mais, um contingente equivalente à população infantil de 0 a 14 anos de idade. O Brasil será o sexto país com o maior número de idosos, ou seja, 55 milhões de pessoas acima dos 60 anos $^{1}$. Isso fará com que a proporção de idosos na população total alcance $14,2 \%$ da população em 2050 , podendo esta conquista ser atribuída à queda da natalidade associada à queda da mortalidade ${ }^{2}$. Estudos demonstram que, com o aumento na expectativa de vida, solidificam a importância da espiritualidade e religiosidade entre os idosos como um recurso importante e necessário para o enfrentamento de situações adversas ${ }^{3}$. A espiritualidade, na ampla concepção da palavra, é um estado que o homem quer chegar a ser, isto é, ir ao encontro de Deus e do Divino ${ }^{4}$. Ela encontra-se dentro de nós, está presente em nossas vidas, nos sentidos e nos sentimentos, portanto, podemos considerá-la uma dimensão humana, instigando-nos a acreditar em alguma força ou ser superior e a vivenciá-la de forma diferenciada 5 .
Já a religião é um sistema organizado de crenças, práticas, rituais e símbolos destinados a facilitar a proximidade do indivíduo com o sagrado ou o transcendente ${ }^{6}$. Neste sentido, os símbolos sagrados e a crença religiosa fazem parte da cultura humana há muitos milênios, utilizadas em diferentes situações e são imprescindíveis em momentos de crise, pois fornece vínculos e valores, promovendo desfechos em momentos de grande afetividade ou em situações de doença, perda da vitalidade e na eminência da morte ${ }^{7}$. Os ornamentos religiosos (terços, santinhos, panfletos, Bíblia) são âncoras indicativas das necessidades espirituais de pacientes e familiares e devem ser valorizados em situações de crise $^{8}$. Neste viés, Durkhein ${ }^{9}$ enfatiza que a religião, por meio dos símbolos religiosos, é uma forma de negociação com o Divino.

Entende-se que os símbolos acompanham o homem desde épocas remotas e que por intermédio deles desenvolve sua fé e sua religiosidade. Os símbolos são presenças importantes que ligam o ser humano ao Criador e são portais para a abertura da compreensão da imensidão da vida. Nas situações de dor e sofrimento, os símbolos sagrados passam a ter uma relação mais íntima com o racional e o irracional, a razão e a emoção, a dimensão 
física e a dimensão mental/espiritual, o natural e o sobrenatural, o alívio e a dor, a vida e a morte ${ }^{10}$.

Considerando os aspectos acima, o presente estudo foi desenvolvido com o objetivo de conhecer a crença dos idosos em símbolos sagrados, identificando-os os que mais creem e têm fé e como estes os ajudam nas diferentes situações da vida.

\section{Materiais e métodos}

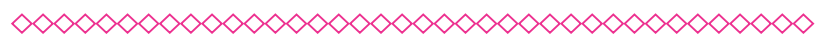

Desenvolveu-se um estudo observacional do tipo transversal nos trinta bairros da cidade de Chapecó (SC). A amostra investigada foi de 2.160 indivíduos, distribuídos em amostragem proporcional com relação às faixas etárias de 20 a 39 anos, 40 a 59 anos e acima de 60 anos, totalizando 720 indivíduos entrevistados em cada grupo. Todo o processo de pesquisa obedeceu criteriosamente os preceitos éticos dispostos na Resolução n. 196/1996 do Conselho Nacional de Saúde, que trata das pesquisas com seres humanos. A pesquisa foi iniciada após aprovação pelo Comitê de Ética em Pesquisa da Pontifícia Universidade Católica do Rio Grande do Sul, sob o protocolo e registro CEP de n. 08/04149. Em respeito à ética, todos os participantes assinaram o Termo de Consentimento Livre e Esclarecido e tiveram suas identidades preservadas.

As residências foram sorteadas utilizando a tabela de números aleatórios e foram avaliados quantos moradores viviam na residência e suas respectivas idades. Foram entrevistadas três pessoas de cada família, obedecendo as faixas etárias estabelecidas.

Para definição do tamanho da amostra, utilizou-se como base de cálculo a estimativa obtida pela questão referente à existência de elementos espirituais que foi de $67,0 \%(n=1444)$. Desta forma, assumindo um nível de significância de $1 \%$ $(n=0,01)$ e um erro relativo máximo de $3,7 \%$, o tamanho mínimo de amostra ficou definido em 2.160 pesquisados.

Utilizamos um questionário com perguntas semiestruturadas. As entrevistas foram realizadas pela pesquisadora e por dez estudantes de Enfermagem devidamente treinadas. Isso ocorreu en- tre julho de 2008 e janeiro de 2009, de segunda a sexta-feira, nos período matutino e vespertino.

Para análise estatística, utilizou-se o programa SPSS 13.0 e foi desenvolvida por meio da análise descritiva univariada, obtenção das frequências simples e relativas para cada variável investigada. Para a análise comparativa (bivariada), foi realizado o teste Qui-quadrado de Pearson e o coeficiente de contingência. Quando as faixas etárias foram comparadas com variáveis dicotômicas de respostas do tipo sim/não, também foi considerada na inferência a prova de tendência linear do Qui-quadrado (linear-by-linear). Considerando as variáveis categóricas ordinais, quando comparadas à faixa etária, foi utilizado o coeficiente de correlação de Spearman ${ }^{11}$.

\section{Resultados}

$\infty<\infty<\infty<\infty<\infty<\infty<\infty<\infty<\infty<\infty<\infty<\infty<\infty<\infty<\infty<\infty<$

Dos 2.160 pesquisados, $57,0 \%(n=1.223)$ eram do sexo feminino e $43,0 \%$ ( $n=937$ ) do sexo masculino. A amostra apresentou um predomínio do sexo feminino $(p<0,001)$. Quanto ao estado civil, observou-se prevalência de casados $52,7 \%(n=1.137)$, solteiros $18,3 \%(n=394)$ e de $11,9 \%(n=257)$ de viúvos.

Em relação ao estado civil e à faixa etária, foi detectada diferença estatisticamente significativa $(p<0,001)$, de forma que o estado civil solteiro se mostrou significativamente associado à faixa etária de 20 a 39 anos, os separados com a faixa etária de 40 a 59 anos e viúvos com os de 60 anos ou mais.

Quanto à etnia, 48,0\% ( $n=1.027)$ dos pesquisados declararam-se da etnia brasileira, 32,2\% ( $n=689)$ italiana e $11,5 \%(n=247)$ alemã. Também foram obtidas declarações de etnias afrodescendentes, com $1,7 \%(n=36)$, e indígena, com $2,0 \%$ $(n=42)$.

Quando questionados sobre a existência de símbolos espirituais, houve predomínio da afirmativa na crença de existência destes, mencionada por $68,5 \%(n=1.460)$ da amostra, enquanto que $28,1 \%(n=599)$ relataram não acreditar. Também se observou a resposta em que os pesquisados não souberam ou não sabem da existência de símbolos 
espirituais apontados por $3,4 \%(n=72)$ dos pesquisados.

Considerando a comparação em relação à faixa etária, observou-se diferença estatisticamente significativa $(p<0,05)$ de que a faixa etária de 60 anos ou mais se mostrou associada a crença na não existência de símbolos espirituais, enquanto que na faixa etária de 40 a 59 anos houve a afirmação da existência de símbolos espirituais. Quanto à faixa etária de 20 a 39 anos, a associação não se mostrou relevante com nenhuma das categorias do questionamento referente à existência de símbolos espirituais (figura 1 ).

Realizou-se uma avaliação mais detalhada da faixa etária acima de 60 anos, subdividindo nas idades de 60 a 69, de 70 a 79 e acima de 80 anos, na busca de um melhor entendimento sobre as informações obtidas. De acordo com os resultados, pode-se evidenciar que, quanto mais elevada a faixa etária, maior foi a crença na existência de símbolos espirituais. Conforme o resultado do teste Qui-quadrado, foi detectada associação estatística significativa $(p<0,001)$ em que os pesquisados, entre 60 e 69 anos, se mostraram associados à dúvida sobre a existência de símbolos espirituais. 0 grupo com idades entre 70 e 79 anos apresentou tendência de associação com a afirmativa para crença da existência de símbolos espirituais, enquanto que houve a associação significativa com a crença na existência de símbolos espirituais naqueles com idade superior a 80 anos.

Na figura 2 é possível verificar a distribuição relativa obtida com base no total de cada faixa etária para a resposta positiva à existência de símbolos espirituais.

Ainda em relação à faixa etária acima de 60 anos, vale salientar que, dos 25 pesquisados que informaram a resposta "não sei/talvez", 92,0\% $(n=23)$ deles encontravam-se entre 60 e 69 anos. Ou seja, os pesquisados de 70 anos ou acima de 80 anos se mostraram mais decididos no sentido ${ }^{3}$ de crer ou não crer na existência de símbolos espirituais.

Quando solicitados a nomear os símbolos em que tem fé ou acredita (figura 3$), 47,3 \%(n=1.014)$ afirmaram a crença na Bíblia; $20,4 \%(n=438)$ na crença em imagens de santos. Observou-se que
$10,1 \%(n=216)$ relataram ter fé em Deus, Jesus e em santos.

Para análise comparativa em relação à faixa etária, foi detectada associação estatisticamente significativa $(p<0,001)$, sendo que na faixa de 60 anos ou mais a associação se deu com as imagens de santos e com a composição Bíblia, rosário, imagens ou figuras de santos.

Entre aqueles com idade de 40 a 59 anos, a associação ocorreu com a crença na Bíblia e a tendência de associação com a composição Bíblia, imagens e amuletos. Na faixa etária dos 20 aos 39 anos, foi observada associação com amuletos, imagens de santos e com a categoria "não acreditam em nada". Ainda em relação ao tópico símbolos em que acredita ou tem fé, chama atenção o quanto a faixa etária de 20 a 39 anos se mostrou não associada de forma significativa às categorias Bíblia e rosário.

No questionamento se os símbolos espirituais ajudam ou não nas diferentes situações da vida (figura 4), $73,9 \%$ ( $n=1.330$ ) confirmam que os elementos espirituais os ajudam e $19,8 \%(n=357)$ não acreditam nesta possibilidade. Avaliando os resultados pela faixa etária, o teste Qui-quadrado apontou associação estatisticamente significativa $(p<0,01)$, de modo que os pesquisados com 60 anos ou mais apresentaram associação significativa com a não crença que os símbolos os ajudam, bem como com a categoria não sabe/indiferente. Em relação à faixa etária de 40 a 59 anos e de 20 a 39 anos, foi detectada tendência de associação com a afirmativa de que os símbolos espirituais os ajudam.

Vale salientar que na faixa etária de 20 a 39 anos ficou evidente a não associação com o fato de não saber ou ser indiferente ao fato dos símbolos espirituais os ajudarem, ficando suas respostas restritas às opções sim e depende.

Deve-se estar atento ao fato de que a categoria referente à resposta não sabe/indiferente foi mencionada por 29 pesquisados, e destes $55,2 \%$ $(n=16)$ pertenceram à faixa etária de 60 anos ou mais. Desta forma, entre aqueles que responderam que não sabem ou são indiferentes se os símbolos espirituais os ajudam existe, uma grande chance $(55,2 \%)$ de que pertençam à faixa etária acima de 60 anos. 
Estratificando a faixa etária acima de 60 anos, nas idades de 60 a 69, de 70 a 79 e acima de 80 anos, foram evidenciadas associações significativas, segundo o teste Qui-quadrado de Pearson $(p<0,001)$, de forma que os pesquisados de 60 a 69 anos se mostraram exclusivamente associados a não saberem ou serem indiferentes sobre se os símbolos os ajudam; entre os de 70 a 79 anos, a associação ocorreu, exclusivamente, com a negativa para este tema. Em relação aos pesquisados acima de 80 anos, a associação se deu com a resposta afirmativa para a ajuda dos símbolos espirituais. A figura 5, que traz a distribuição relativa com base no total de casos em cada faixa etária, permite verificar a proporção de pesquisados que declararam acreditar que os símbolos espirituais os ajudam.

\section{Discussão}

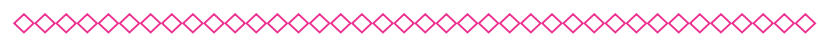

Os achados do presente estudo reafirmam a importância de se investigar a crença em relação à existência de símbolos espirituais e como estes os ajudam no processo de envelhecimento. Conforme os dados obtidos dos 2.160 pesquisados, $57,0 \%$ $(n=1.223)$ eram do sexo feminino, $52,7 \%(n=1.137)$ eram casados, $48 \%(n=1.027)$ de etnia brasileira, $28 \%(n=603)$ informaram possuir o nível secundário completo e em relação ao nível socioeconômico $84,5 \%(n=1808)$ recebiam de um a quatro salários mínimos.

Dos pesquisados, $68,5 \%(n=1.460)$ acreditavam na existência de símbolos espirituais, $28,1 \%$ $(n=599)$ relataram não acreditar e $3,4 \%(n=72)$ não souberam responder sobre a existência ou não de símbolos espirituais. Quando estratificados por faixa etária, observou-se que quanto maior a faixa etária, maior é a crença na existência de símbolos espirituais. Frente aos achados, pode-se inferir que, com o aprofundamento do envelhecimento, os idosos tornam-se mais espiritualizados e olham com mais serenidade para a vida, ampliando a fé, aproximando-se de Deus, acreditando nos símbolos e forças espirituais, exercitando mais suas práticas espirituais (preces, orações, súplicas).

Soares $^{12}$ aponta que $93 \%$ dos brasileiros acreditam na força das orações, 38\% acreditam na força dos passes, assim como também relatam a crença nos anjos da guarda, no céu e nos espíritos do bem.

Batista $^{10}$ demonstrou em sua pesquisa com adultos internados em Unidades de Terapia Intensiva (UTI) que eles portam objetos em que depositam a sua fé, como rosários, fita benzidas, medalhas, figuras de santos, crucifixo e patuá. Nas entrevistas realizadas, verbalizam a sua crença em Deus, na Virgem Maria, demonstrando que objetos sagrados e a religião assumem um papel significativo na manutenção da dignidade, da liberdade e da integridade do ser em situações estressantes e angustiantes.

Estudo realizado por Zenevicz ${ }^{13}$ com docentes chapecoenses demonstrou que consideram a presença de espíritos e mentores influenciando em suas atividades diárias, a alma, a oração, a fé, a Bíblia, seguida do terço/rosário, a vida, a ética e a moral; proximidade de almas gêmeas; a supremacia do bem sobre o mal; o equilíbrio da natureza; sensações de paz, serenidade, harmonia e compaixão; figuras de santos, livros, o toque, como objetos ou elementos espirituais.

Almeida e Monteiro ${ }^{14}$ salientaram que com 0 aumento da idade as pessoas se tornam mais religiosas. A ligação das pessoas com o divino provém de suas crenças em Deus, em Jesus Cristo, em santos, em anjos e em entidades espirituais. Estas crenças influenciam o bem-estar subjetivo, favorecendo a interação social e promovendo coerência nas ações e dando um significado à vida ${ }^{15}$.

Em relação aos elementos em que acreditam e tem fé, $47,3 \%(n=1.014)$ relataram acreditar na Bíblia, 20,4\% ( $n=438)$ acreditavam em imagens de santos, $10,1 \%(n=216)$ referiram fé em Deus, Jesus e em santos. Sabe-se que o homem é um ser religioso e desde tempos imemoriais os símbolos sagrados ocupam um espaço de imenso valor na vida humana. Acreditar e confiar nesses símbolos independe de serem concretos ou subjetivos, pois transitam entre o racional e o irracional, a razão e a emoção, a matéria e a memória, o natural e o sobrenatural, o alívio e a dor, a vida e a morte ${ }^{10}$. Tê-los por perto em situações estressantes permite uma experiência divina, em que estes desempenham um papel de relevância. Representam o 
sobrenatural capaz de resolver o que a ciência não consegue, fornecendo garantias que se a ciência falhar há um "ser divino", "uma força poderosa", "uma entidade" que poderá fazê-lo9. Os símbolos demonstram a existência de Deus na psique humana e possibilita o homem conectar-se com o divino ${ }^{16}$.

Jung ${ }^{17}$ enfatizou que os símbolos podem ser conceituados como formas estruturadas e representativas dos sentimentos, das crenças ou de ações que não podem ser expressas por palavras, mas encontram-se presentes na vida de todos os seres humanos que e nelas acreditam. A Bíblia, um livro cultuado por muitos, traz ensinamentos e a possibilidade de o homem descobrir-se, mudar o rumo de sua vida e conhecer-se melhor. Ler e estudar a Bíblia amplia a oportunidade de estudar a si próprio, analisando as possibilidades de um jeito único e pessoal, descobrindo potencialidades dentro das particularidades individuais ${ }^{18}$.

Nesta ótica, Eliade ${ }^{19}$ ponderou que na busca de respostas aos anseios, sonhos e esperanças, as pessoas criam os símbolos necessários a orientação e ordenação do mundo em que vivem, e, especialmente em momentos difíceis da existência, a experiência religiosa se manifesta em toda a sua plenitude demonstrada com uma relação de proximidade com o sagrado.

E é nesta visão que Peres ${ }^{20}$ reafirmou que o homem precisa acreditar, precisa ter fé, mesmo que seja em algo abstrato ou concreto. 0 sentimento de ter fé amplia a confiança e auxilia na estabilidade das emoções, permitindo a sensação da calma, clareando sentimentos, aumentando conhecimentos e possibilitando alcançar os objetivos. A fé religiosa permite um diálogo com o criador, semeando no âmago confiança, dando forças e apoio além de nosso corpo físico.

Já a pesquisa realizada por Batista ${ }^{10}$ mostrou que os objetos sagrados representam um símbolo de amparo transcendental, possibilitando a comunicação com o Criador, nos fortalecendo, proporcionando alegria, segurança e diminuindo a ansiedade. Nesta linha de raciocínio, os símbolos religiosos são fontes de manifestação terrena do sagrado. Os ornamentos religiosos, os terços/rosários, os santos, os panfletos religiosos e a Bíblia são fontes não verbais que indicam possíveis ne- cessidades espirituais/religiosas que demonstram fé e devem ser valorizadas ${ }^{8,21}$.

Zenevicz ${ }^{22}$ assinalou que embora não seja possível determinar com exatidão a existência ou não de coisas espirituais, estas representam pontos que interligam as pessoas com a vida espiritual ou religiosa. A espiritualidade está entrelaçada a questões sobre o significado e o propósito da vida, e a crença em algo ou em alguém proporciona significado, alento e coragem. Acreditar em algo que transcende a compreensão humana evidencia-se, principalmente, nos momentos mais dolorosos, na esperança de melhora, na busca da amenização para os ferimentos do corpo e da alma ou no agradecimento pela cura. Bordieu ${ }^{23}$ enfatiza que "milagres acontecem para quem acredita e a crença legitima o simbólico".

Em relação ao questionamento se os elementos espirituais os ajudam ou não nas diferentes situações do viver envelhecendo, 73,9\% $(n=1.330)$ confirmaram que os elementos espirituais os ajudam e 19,8\% ( $n=357)$ não acreditam nesta possibilidade. Sabe-se que os símbolos sagrados são legitimados pela sociedade e possuem uma magia não perceptível, mas que alimenta a alma ${ }^{24}$. Enfim, toda a religião procura compreender o mundo por meio de símbolos que, articulados entre si, revelam e constroem a realidade, estabelecendo uma relação de fé no invisível, que liga o homem ao transcendente ${ }^{25}$. A fé se baseia em crer, proporcionando um diálogo entre o ser humano e o divino, recebendo forças e apoio além do corpo físico. Acreditar confere confiança e estabilidade, proporcionando calma. Amplia a capacidade de determinação em busca de objetivos ${ }^{26}$.

Soares e Nóbrega ${ }^{27}$ demonstraram que a estimulação do uso de objetos ou amuletos e a realização de atividades como leituras ou músicas religiosas são apontadas como suporte e estímulo na busca da fé, tendo a finalidade de propiciar às pessoas doentes um nível de bem-estar espiritual.

Os símbolos sagrados e a crença religiosa fazem parte da cultura humana há muitos milênios. 0 sagrado é aquilo que transcende a razão humana, interligando o humano ao divino e resiste a qualquer intervenção racional ${ }^{28}$. Os símbolos sagrados e a expressão religiosa das pessoas são imprescindíveis em momentos de crise, pois for- 
nece vínculos e valores, promovendo desfechos em momentos de grande afetividade e em situações de doença, perda da vitalidade e na eminência da morte $^{7}$. Contribuindo neste aspecto, Souza ${ }^{29}$ afirmou que as pessoas, em situações caóticas, procuram buscar apoio em algo que creem que lhes dá força e incentivo para lutar pela vida. Igualmente desta fé em algo superior e transcendente emergem esperanças e motivação para continuar a lutar e superar as dificuldades presentes ${ }^{30}$.

Penha ${ }^{8}$ salientou que os ornamentos religiosos (terços, santinhos, panfletos, Bíblia) são âncoras indicativas das necessidades espirituais de pacientes e familiares e devem ser valorizados em situações de crise.

\section{Conclusão}

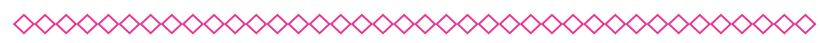

Frente aos resultados deste estudo, pode-se deduzir que os símbolos são impregnados de significados, necessários e importantes ao homem religioso, principalmente no avançar do envelhecimento. Estiveram e estão presentes não somente na trajetória religiosa, mas na evolução da humanidade, exercendo um papel de representação dos ideais de explicação aos fatos que fogem a compreensão humana e das coisas invisíveis aos olhos.

Conclui-se que os idosos dão um valor maior aos símbolos espirituais, pois servem de âncora nas situações de conflito, dor, sofrimento e morte. Utilizando estes símbolos e participando de suas manifestações divinas, as pessoas são despertadas para a fé que fundamenta todas as coisas que se esperam e a prova das coisas que são invisíveis aos olhos.

O símbolo espiritual em que depositam mais fé é a Bíblia, seguidas pelas figuras de santos, em Deus e Jesus. Ao utilizarem-se destes símbolos espirituais, os seres humanos expressam a sua espiritualidade de várias maneiras, religiosas ou não religiosas, utilizando metáforas, imagens, rituais, poesia, arte e música. Esta linguagem verbal ou não verbal rica em simbolismos diferencia-se dependendo da cultura. É uma forma simbólica de entendimento do mundo, um portal que se atravessa para entender melhor a realidade espiritual.
Enfim, descortina-se para o homem religioso a compreensão da vida como um bem supremo e sua essência espiritual. Desperta o sentimento religioso que pode ser definido como a mais completa e intrigante essência do coração humano, onde residem as respostas a todas as inquietações e aspirações, sonhos e entusiasmos, alegrias e indagações mais profundas sobre a vida, o além, o universo e, principalmente, quem somos nós, de onde viemos e para onde vamos. Desta forma, conclui-se que espiritualidade e a religiosidade desempenham um papel de relevância na vida cotidiana dos idosos.

\section{Referências}

$\infty \times \infty \times \infty \times \infty \times \infty \times \infty \times \infty \times \infty \times \infty \times \infty \times \infty \times \infty \times \infty$

1. Andrews GA. Los desafíos del proceso de envejecimiento en las sociedades de hoy y del futuro. In: Encuentro Latino Americano Y Caribe sobre las personas de edade. 1999. CELADE. Santiago.

2. IBGE - Instituto Brasileiro de Geografia e Estatística, 2002. Dados sobre População do Brasil, PNAD (Pesquisa Nacional por Amostra de Domicílios) 2001.

3. Sommerhalder C, Goldstein LL. O papel da espiritualidade e da religiosidade na vida adulta e na velhice. In Freita EV., Cançado LPyFAX., Gorzoni ML. (Eds.).

4. Levin J. Deus, fé e saúde: explorando a conexão espiritualidade-cura. São Paulo: Ed Cultrix; 2001.

5. Faria JB, Seidl EMF. Religiosidade e enfrentamento em contextos de saúde e de doença: uma revisão de literatura. Psicol.Reflex. Crit. 2005;18(3).

6. Koenig HG, McCullough ME, Larson DB. Handbook of religion and health. New York: Oxford University; 2001.

7. Kubler Ross E. Sobre a morte e o morrer. 6.ed. São Paulo: Martins Fontes; 2000.

8. Penha RM. A expressão da dimensão espiritual no cuidado de enfermagem na UTI [dissertação 
de mestrado]. Universidade de São Paulo-USP. São Paulo: 2008.

9. Durkhein E. As formas elementares da vida religiosa: o sistema totêrmico na Austrália. Tradução de Paulo Neves. São Paulo: Martins Fontes; 2003.

10. Batista MA. Presença do sagrado em um momento crítico: internação em unidade de terapia intensiva [dissertação de Mestrado]. Universidade Católica de Goiás: 2001.

11. Barbetta PA. Estatística aplicada às ciências sociais. 2.ed. Florianópolis: Ed. da UFSC; 1998.

12. Soares C. Em que você acredita? Revista Seleções. 2008.

\section{Zenevicz LT. Práxis educativa: a} espiritualidade como uma dimensão a ser incorporada pelos professores e cuidadores da saúde [monografia pós em Educação Superior] Chapecó: Universidade Comunitária Regional de Chapecó; 2008

14. Almeida R, Monteiro P. Trânsito Religioso no Brasil. São Paulo em perspectiva. São Paulo: 200;15(3).

15. Ellison CG. Religion, the life stress paradigm, adn the study of depression. In: Levin JS (Org.). Religion in aging and health. Thousand Oaks, CA: Sage.

16. Cavalcanti R. O retorno do conceito do sagrado na ciência. In. Teixeira EFB, Muller MC, Silva JDT (Orgs.). Espiritualidade e qualidade de vida. Porto Alegre: EDIPUCRS; 2004.

17. Jung CG. Estudos psicologia analítica. Obras completas vol.VII. Petrópolis: Vozes; 1990.

18. Vicente RB. Bíblia: reconciliação como caminho para a individualização. Psicologia Argumento. 2001;19(29):7-25.

19. Eliade M. O sagrado e o profano. Trad. Rogério Fernandes Fontes. São Paulo: Martins Fontes; 1996.

20. Peres J. Psicoterapia e Espiritualidade: convergência possível e necessária. In: Teixeira
EFB, Muller MC, Silva JDT (Orgs.). Espiritualidade e qualidade de vida. Porto Alegre: Edipuc; 2004.

21. Matos APde. Os símbolos e a simbologia religiosa: 0 papel da igreja Católica. In: Anais do II Encontro do GT Historio das Religiões e das religiosidades. Revista Brasileira de Historia das Religiões - ANPUH. 2009;1(3).

22. Zenevicz, LT. A dimensão espiritual no processo de viver envelhecendo [tese de doutorado]. Porto Alegre: Pontifícia Universidade Católica do Rio Grande do Sul;2009.

23. Bourdieu P. O poder simbólico. Rio de Janeiro: DIFEL; 1989

24. Mauss, M. Sociologia e antropologia. São Paulo: EPU; 1974.

25. Paleari G. Religiões do povo: um estudo sobre a inculturação. São Paulo: Edições; 1991.

26. Roberto GL. Espiritualidade e Saúde. In: Teixeira EFB, Muller MC, Silva JDT (Orgs.). Espiritualidade e qualidade de vida. Porto Alegre: EDIPUCRS; 2004

27. Soares MS, Nobrega MML. Cuidados de Enfermagem a uma Paciente com AIDS a luz da variável espiritual do Modelo Teórico de Betty Neumann. Ciência, Cuidado e Saúde. 2004; 3(2):187-94

28. Jorge JS. Cultura religiosa: o homem e o fenômeno religioso. São Paulo: Loyola; 1998.

29. Souza M. de et al. Humanização da abordagem nas Unidades de Terapia Intensiva. Rev Paul Enferm. 1985; 5(2):77-9.

30. Barreto SM, Gordilho A, Kalache A, Camarano AA, Coimbra JRC, Caldas C, et al. Gênero e desigualdades em saúde entre os idosos brasileiros. In: Oficina de Trabalho sobre desigualdades sociais e de gênero em saúde de idosos do Brasil. 1, 2000. Ouro Preto. I Oficina de trabalho sobre desigualdades sociais e de gênero em saúde de idosos no Brasil. Ouro Preto: NESPE; 2002. 


\section{Anexos}

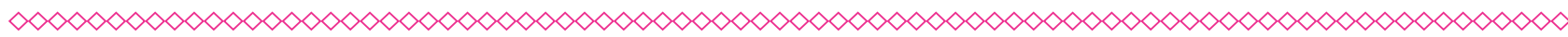

Figura 1 - Distribuição relativa da existência de símbolos espirituais, segundo a faixa etária

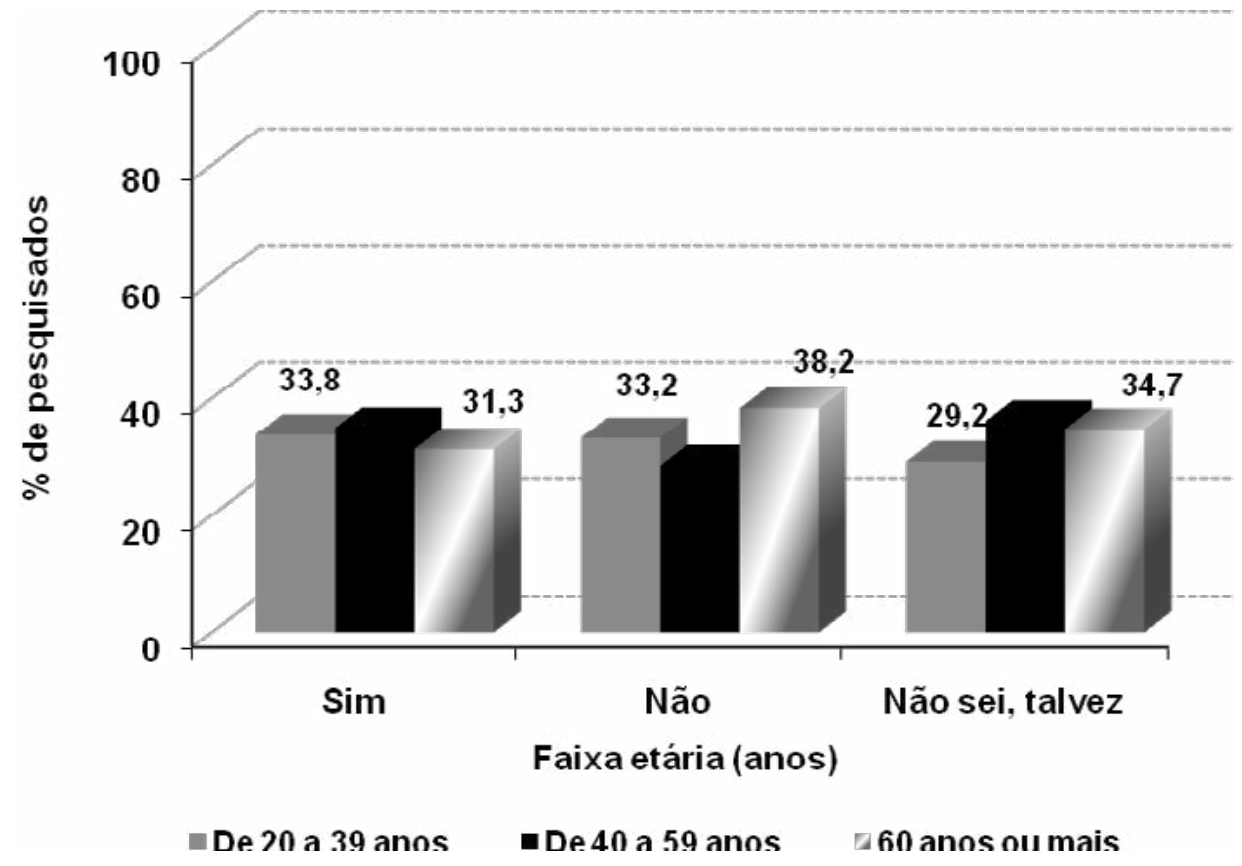

Fonte: elaboração dos autores.

(clique para voltar ao texto)

Figura 2 - Distribuição relativa, obtida pelo total de pesquisados em cada faixa etária, para a resposta afırmativa (sim) para crença na existência de símbolos espirituais, segundo a faixa etária

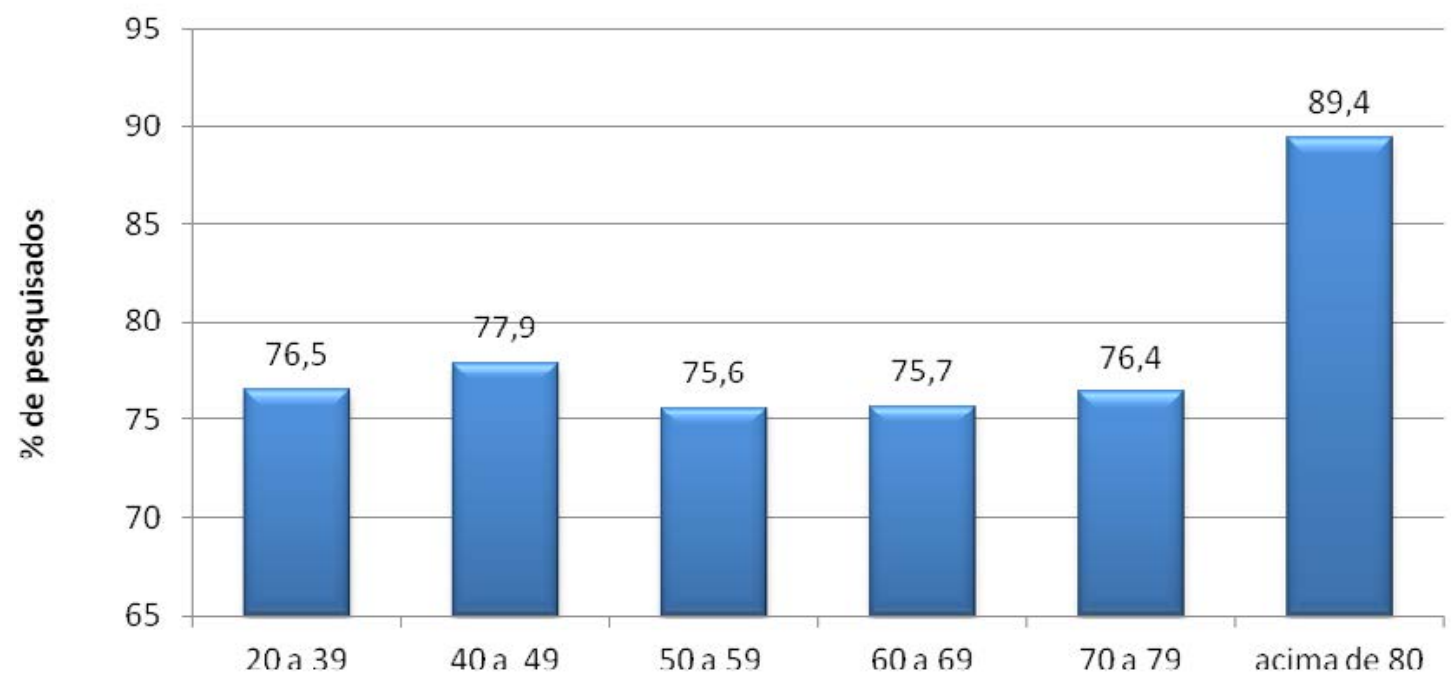

faixas etárias

Fonte: elaboração dos autores.

(clique para voltar ao texto) 
Figura 3 - Distribuição relativa dos símbolos que acredita ou tem fé, segundo a faixa etária

Bíblia, rosário, imagens e..

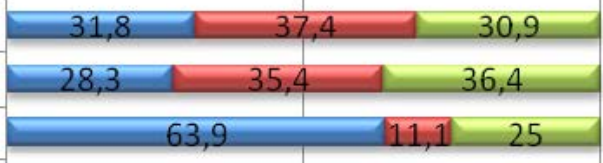

Figuras de Santos Imagens de Santos

Outra

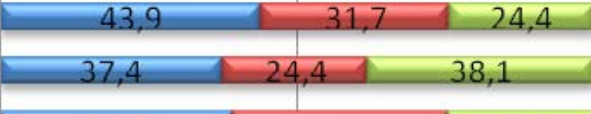

Biblia, rosário

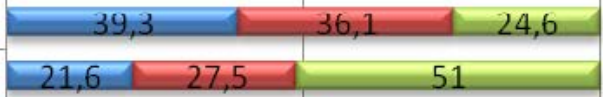

- 20 a 39 anos

- 40 a 59 anos

$\square 60$ anos ou mais

Bíblia, rosário, imagnes e..

Biblia, Imagens e amuletos

Deus, Jesus e outros santos

Não acredita

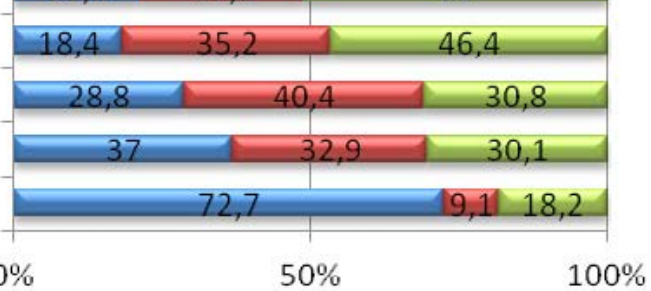

$0 \%$

$50 \%$

(clique para voltar ao texto)

Fonte: elaboração dos autores.

Figura 4 - Distribuição relativa sobre se os símbolos espirituais o ajudam, segundo a faixa etária

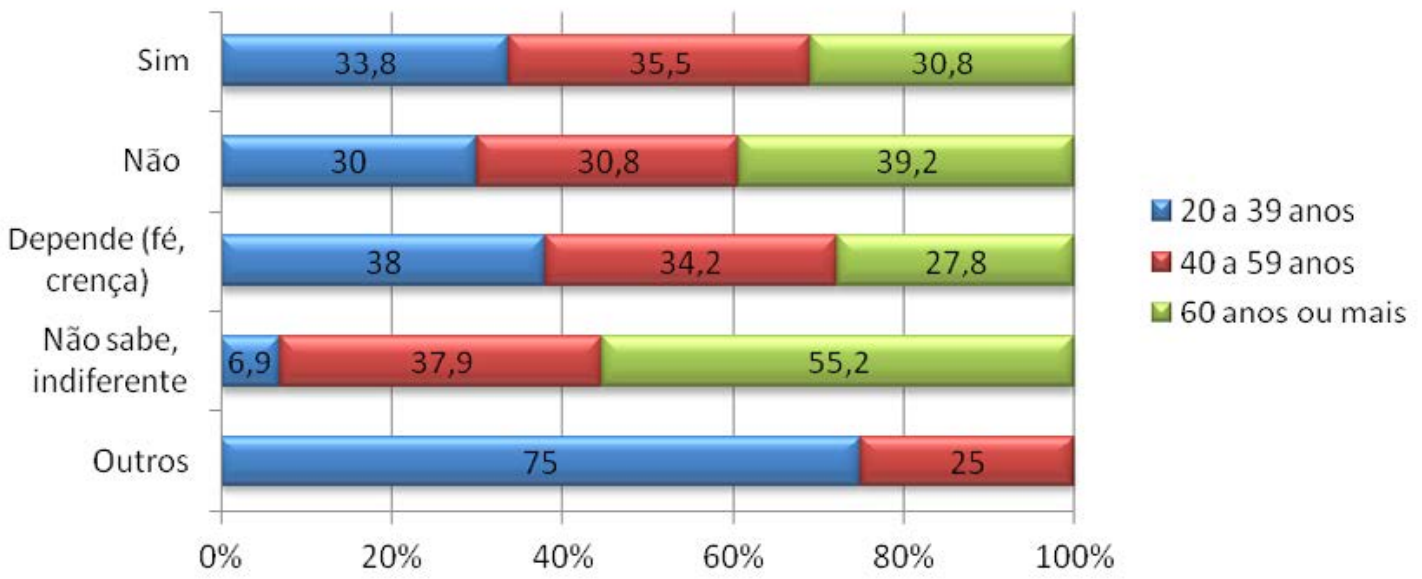

Fonte: elaboração dos autores.

(clique para voltar ao texto) 